\title{
Imbricações teóricas entre comunicação e gestão da informação e do conhecimento na Ciência da Informação
}

\author{
Sely Maria de Souza Costa* \\ Fernando César Lima Leite`
}

Artículo recibido:

1 de marzo de 2016

Artículo aceptado:

27 de septiembre de 2016

\section{Resumen}

En este artículo son discutidas las relaciones conceptuales entre comunicación de la información, gestión de la información y gestión del conocimiento desde el ámbito de las Ciencias de la Información con el objetivo de presentar una fundamentación teórica sobre estos temas con base en la literatura, las reflexiones de diversos autores y los resultados de estudios realizados durante casi 10 años que discurren sobre aspectos epistemológicos de las Ciencias de la Información. El enfoque interdisciplinario permite abordar autores representativos de las Ciencias de la Información, de comunicación, de gestión de la información y de gestión del conocimiento. A lo largo de la discusión son presentados modelos que ilustran los abordajes de autores pioneros, así como las construcciones teóricas que

\footnotetext{
* Universidade de Brasília, Brasil selmar@unb.br fernandoc@unb.br
}

INVESTIGACIÓN BIBLIOTECOLÓGICA, vol.32, núm.74, enero/marzo, 2018, México, ISSN: 2448-8321. pp. 225-249 
muestran las relaciones conceptuales más importantes entre los temas presentados. Se concluye que un abordaje que considera las relaciones antes descritas deben ser privilegiadas en las Ciencias de la Información, lo que a su vez requiere una adopción de los abordajes asociados a comunicación y gestión en los diversos contextos, lo que implica que estudios de comunicación y de gestión en las Ciencias de la Información deben tener en cuenta sus abordajes conceptuales, teóricos inherentes, en la medida que son conceptos cuyos abordajes tienden a estar formalmente asociados en el área.

Palabras clave: Comunicación de la Información; Gestión de la Información; Gestión del Conocimiento; Creación de Conocimiento; Compartir el Uso del Conocimiento; Abordaje Epistemológico de las Ciencias de la Información

Theoretical overlaps between communication and information and knowledge management in Information Science

Sely-Maria de Souza-Costa, Fernando-César Lima-Leite

\section{Abstract}

This paper examines conceptual relationships among communication of information, information management and knowledge management from the standpoint of Information Science in order to proffer a theoretical framework supported by a review of the literature and reflections researchers, who have addressed epistemological aspects of information science in regard to these issues. The approach of this research is interdisciplinary, admitting seminal authors from both information and communication science, as well as research in the field of information and knowledge management in order to describe approaches and theoretical constructions of the most influential researchers and show the key conceptual relationships common in their work. These theoretical commonalities should be taken seriously in the field of information science, which should adopt a research approach that associates communication and management across diverse contexts recognizing their conceptual communalities.

Keywords: Communication of Information; Information Management; Knowledge Management; Knowledge Creation; Knowledge Sharing and Use; Epistemological Approach of Information Science 


\section{INTRODUÇÃO}

$\mathrm{A}_{\text {cionadas com a comunicação científica como fenômeno central de inte- }}^{\text {Ciêna da Informaco tem estudado, desde a sua ênese, questões rela- }}$ resse, uma vez que a disciplina surgiu em razão da preocupação de cientistas, tecnólogos e documentalistas de meados do século passado com os fluxos da informação em ciência e tecnologia. Entretanto, ao longo das últimas décadas identifica-se expansão considerável nos fenômenos de interesse da área. Além da diversificação de fenômenos de interesse, os contextos em que a comunicação tem sido estudada vêm sendo igualmente ampliados. O alargamento no foco de estudos da área decorre, portanto, da identificação desses fenômenos e contextos, os quais, por sua vez, requerem novas abordagens.

Considerando que tal cenário não parece estar sendo claramente explorado nos estudos da área em razão do não reconhecimento desse alargamento no foco dos estudos por parte de alguns teóricos, o presente artigo visa à contribuir para o enriquecimento das discussões. Tal contribuição diz respeito às relações conceituais observadas entre comunicação e gestão como fenômenos da Ciência da Informação desde sua gênese. Portanto, o objetivo deste trabalho é apresentar modelo conceitual que ilustra imbricações teóricas entre comunicação, gestão da informação e gestão do conhecimento na Ciência da Informação. O trabalho resultou da identificação e análise de autores relevantes e seminais da área. Como resultado, discute, de início, questões epistemológicas da Ciência da Informação, as quais compreendem a natureza da área e a informação como seu objeto de estudo. Discute, em seguida, duas questões centrais do artigo. A primeira diz respeito à dimensão da comunicação sob a ótica da abordagem de Belkin (1978) e outros autores, tanto da Ciência da Informação quanto de outras áreas. A segunda trata da compreensão da gestão da informação e do conhecimento como fenômenos da Ciência da Informação, a partir do pensamento de Brookes (1980) associado a outros autores. Conclui com a apresentação gráfica do modelo teórico proposto e explicação textual das relações conceituais embutidas.

\section{AsPectos EPISTEMOLÓGicos DA CIÊNCIA DA INFORMAÇÃo}

O aporte teórico adotado neste artigo mostra a contribuição de estudiosos da área para a fundamentação de pesquisas na Ciência da Informação, iniciando com Borko (1968) e a definição de Ciência da Informação. O autor apresentou sua definição a partir da análise que fez do trabalho de Taylor (1966), o qual, por sua vez, reportou definições e abordagens resultantes das 
discussões realizadas nos congressos do Georgia Institute of Technology. No entanto, apesar da inegável contribuição, tanto das discussões do Congresso, registradas em seus anais, quanto do trabalho de Taylor, em seu artigo para o primeiro volume do Annual Review of Information Science and Technology (ARIST), Borko tem sido reconhecido como o autor da definição seminal - e ainda atual - de Ciência da Informação. Isso porque, a despeito das várias definições encontradas na literatura, até hoje a definição do autor mostra-se apropriada para a área, como bem observa Pinheiro (2005) em sua análise das questões epistemológicas da Ciência da Informação. Nas palavras de autor, portanto, a Ciência da Informação é: "Disciplina que investiga as propriedades e o comportamento da informação, as forças que governam o fluxo da informação e os meios para processar a informação, com o objetivo de atingir acessibilidade e utilidade ótimos" (Borko, 1968:3).

Ainda segundo o autor, a Ciência da Informação preocupa-se com o corpo de conhecimentos relacionados com a origem, coleta, organização, armazenamento, recuperação, interpretação, transmissão, transformação e utilização da informação. Isso inclui a investigação de três tipos de fenômenos, segundo o autor. O primeiro, abordado como as formas de representação da informação em sistemas naturais e artificiais. O segundo, relacionado com o uso de códigos para transmissão eficiente da mensagem. O último, concernente ao estudo dos meios e técnicas de processamento da informação.

Relevantes a serem destacadas, neste ponto, são as duas questões fundamentais para os estudos em Ciência da Informação. A primeira diz respeito à interdisciplinaridade necessária tanto à definição quanto ao escopo, à abrangência e ao marco teórico das pesquisas. A segunda refere-se ao conceito de informação definindo o objeto das pesquisas, em uma variedade de contextos, focos e abordagens, dentre outros aspectos. É essa interdisciplinaridade no estudo da informação que reforça a propriedade dos vínculos entre a comunicação e a gestão na Ciência da Informação, como será mostrado ao longo deste artigo.

No âmbito da Ciência da Informação, são identificados diferentes conceitos, abordagens, contextos e enfoques para a informação. Análise da literatura da área permitiu identificar quatro diferentes - embora complementares -, abordagens. A primeira, da redução de incerteza versus tomada de decisão, identificada nos trabalhos de autores como Pignatari (1968) e como Yovits (1969) e Kochen (1983). A segunda relaciona-se com a noção de sentido (sense making), cujo trabalho considerado relevante é o de Dervin (1977). A terceira, do conhecimento registrado versus substituto físico do conhecimento, cujos autores representativos nesse artigo são Le Coadic (1996) e Farradane (1979). É importante observar que o trabalho de Farradane introduz a noção 
de significado da informação versus necessidade da presença de indivíduos e seus estados mentais, o que, por seu turno, chama o ponto de vista cognitivo para o foco desses estudos. Finalmente, a quarta abordagem identificada diz respeito a estruturas de conhecimento, sendo percebida nos trabalhos de Belkin (1978), Brookes (1980) e Ingwersen (1992), que reforçam e ampliam o ponto de vista cognitivo para os estudos da informação na Ciência da Informação. A seguir, são apresentadas, resumidamente, as definições de cada um desses autores.

Pignatari (1968) considera que a informação se relaciona com seleção e escolha (daquilo que soluciona uma dúvida/preenche uma lacuna). Nesse foco, o autor concebe informação como instruções seletivas. Segundo sua abordagem, só há informação quando há dúvidas, o que pressupõe um conjunto de alternativas (capazes de dirimi-las).

Kochen (1983: 278) apresenta definição similar à de Yovits, em cujas palavras informação constitui "dados de valor para a tomada de decisão". Nas palavras de Kochen, informação são, de fato, dados relevantes para tomada de decisão (sobre o que soluciona uma lacuna, dúvida, necessidade).

Dervin (1977), aparentemente parafraseando Karl Popper, permanece no contexto da tomada de decisão, sugerindo três tipos distintos de informação, com base na interação indivíduo versus ambiente:

- Informação 1, aquela que descreve a realidade, sua estrutura original ou seu padrão, e é externa ao homem;

- Informação 2, que consiste em um repertório subjetivo: as idéias, estruturas ou imagens imputadas ao ambiente externos pelas pessoas;

- Informação 3, que é a forma como cada indivíduo lida com as informações 1 e 2 para consolidar seu processo decisório.

Ou seja, para Dervin há três tipos de informação. A primeira, informação objetiva, externa ao homem e independente deste. A segunda, informação subjetiva, interna, inerente ao homem e independente da realidade objetiva. Finalmente, informação resultante da combinação/interação das duas primeiras, isto é, da decisão que resulta da interpretação do homem dessas duas alternativas (informação 1 e 2). $\mathrm{Na}$ abordagem da autora, a questão do significado atribuído ao que é informação ganha relevância e requer processo de interpretação por parte de um indivíduo.

Em abordagem similar à de Dervin (1977), no sentido em que requer a presença do indivíduo e sua interpretação do que é informação, Farradane (1979) considera a informação "estéril" até que seja vinculada a um indivíduo que a produza ou seja afetado por ela. $\mathrm{O}$ autor analisa a informação como um 
fenômeno mental, enfatizando as diferenças de significado de uma comunicação na percepção de diferentes receptores, de acordo com o estado inicial de conhecimento destes e suas habilidades em entender a informação. No artigo analisado aqui, o autor dá continuidade a discussão anterior (Farradane, 1976), complementando o que definiu como informação: um substituto ou representante físico do conhecimento. Mais que isso, inclui os aspectos cognitivos em suas análises.

Le Coadic (1996), utilizando uma definição análoga - embora com diferente enfoque - à de Farradane, considera informação como conhecimento registrado sob a forma escrita, oral ou audiovisual. Do mesmo modo que Le Coadic, vários autores da área da Ciência da Informação consideram a informação como objeto de pesquisa desde que esta seja produzida como conhecimento registrado.

Belkin (1978) define informação como a estrutura de qualquer texto (estrutura comunicável) capaz de modificar a estrutura cognitiva de um receptor. O texto, nesse caso, consiste de uma mensagem propositadamente estruturada por um gerador que decide comunicar determinado aspecto de seu conhecimento. Para isso, isola-o, modifica-o e o transforma em uma estrutura comunicável - o texto.

Ainda de forma similar a Belkin, no sentido em que adota abordagem relacionada com aspectos cognitivos do indivíduo, Brookes (1980) afirma que conhecimento é um conjunto de conceitos ligados por suas relações e informação é uma pequena parte dessa estrutura. Em sua equação fundamental, ilustrada na Figura 3, Brookes exprime o conceito de informação como um fenômeno que produz efeitos no indivíduo, no sentido em que altera suas estruturas de conhecimento. Segundo o autor, um estado atual de conhecimento, mais um conhecimento novo (obtido por meio de uma nova informação) é igual a um novo estado de conhecimento, resultante do efeito da nova informação.

De forma semelhante e complementar a Belkin, Ingwersen, a partir da perspectiva da Ciência da Informação, considera que o conceito de informação tem que satisfazer a dois requisitos: "Por um lado a informação sendo o resultado da transformação das estruturas de conhecimento do gerador (por intencionalidade, modelo dos estados de conhecimento do receptor, e na forma de sinais); e, por outro lado, sendo algo que, quando percebido, afeta e transforma o estado de conhecimento do receptor" (Ingwersen, 1992: 33 ).

É possível, portanto, observar que, segundo os autores analisados, informação na Ciência da Informação constitui um fenômeno a ser estudado tanto do ponto de vista físico, objetivo (conhecimento registrado em algum tipo de suporte e externo ao homem) quanto do ponto de vista cognitivo, subjetivo 
(processos realizados nos espaços/estruturas mentais dos indivíduos).

É importante ressaltar, neste ponto, a importância da comunicação no foco dos estudos da informação na Ciência da Informação. Nesse sentido, a seção a seguir discute o enfoque da comunicação na Ciência da Informação, a partir do pensamento de Belkin.

\section{Foco na comunicação a Partir do pensamento de Belkin}

Belkin (1978), após exaustiva pesquisa de conceitos de informação definidos no âmbito da Ciência da Informação, apresentou um conceito que reflete aspectos estruturais (cognitivos), nos quais oito requisitos devem ser preenchidos. Esses requisitos, por seu turno, estão agrupados com base em três abordagens, nomeadamente, metodológica ( $\mathrm{M}$ - utilidade do conceito), comportamental (C - fenômeno para o qual o conceito "conta"), e definicional (D - relativo ao contexto do conceito). Conforme a abordagem do autor, portanto, um conceito de informação é apropriado à Ciência da Informação quando:

- refere-se à informação ocorrendo dentro de uma comunicação com propósito e significado; (D)

- leva em conta a informação como um processo de comunicação social entre seres humanos; (D)

- leva em conta a informação como algo que é requerido ou desejado; (D)

- leva em conta a informação como algo que tem efeito em seu receptor; (D; C)

- leva em conta a informação como algo que está relacionado ao "estado de conhecimento" de um gerador e de um receptor; $(\mathrm{D} ; \mathrm{C})$

- leva em conta a informação como tendo variados efeitos quando a mensagem é apresentada por diferentes meios; (C)

- é generalizável para além de casos individuais; (M)

- oferece um meio para predição do efeito da informação. (M)

O conceito de informação de Belkin atende aos oito requisitos propostos por ele em seu trabalho de doutoramento. É relevante destacar que o autor usa a ideia de estrutura inserida na análise do que chama de "sistema de comunicação que interessa à Ciência da Informação” (Belkin, 1978: 81). Tal sistema é, segundo o autor, controlado pelo receptor, instigado por um estado anormal de conhecimento relativo a um tópico, podendo ser estudado nos níveis cognitivo e linguístico (Figura 1). 


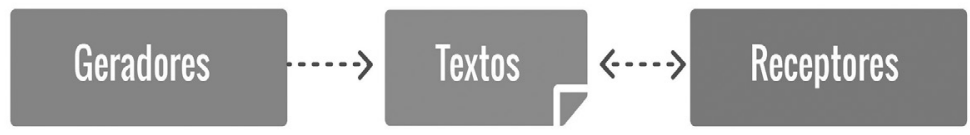

Nivel Linguístico do sistema

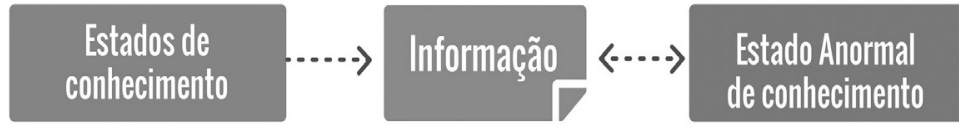

Nível Cognitivo do sistema

Figura 1. Elementos de un sistema de comunicação de interesse da Ciência da Informação Fonte: adaptado de Belkin (1978:81)

No nível linguístico, o autor insere a informação em um processo de comunicação entre seres humanos. Nesse sentido, o conceito conforma um sistema de comunicação em que a informação é associada a um texto (coleção de signos propositadamente estruturados por um gerador com a intenção de modificar a 'imagem-estrutura' de um receptor). Informação associada a um texto, portanto, é a estrutura conceptual de um gerador - que a modifica de acordo com um propósito, uma intenção e o conhecimento do estado de conhecimento do receptor-, e que é subjacente à estrutura da superfície (isto é, a linguagem) daquele texto. A Figura 2 ilustra a abordagem do autor no nível lingüístico, ou seja, relativa a um processo de comunicação da informação.

É interessante notar que estudiosos da comunicação humana a definem com os atributos utilizados por Belkin em sua construção do conceito de informação para a Ciência da Informação no nível linguístico. Veja-se, por exemplo, no modelo de Tubbs e Moss (2003), os elementos que compõem o processo de comunicação. São eles: comunicadores 1 e 2 (respectivamente emissor e receptor, em outros autores), insumo (estímulos em ambos para a comunicação), filtros (utilizados pelos dois comunicadores), mensagem, interferências, canal e retroalimentação. Destaca-se, nos estudos dos autores, a relevância das intenções do emissor sobre provocar efeitos no receptor, ao emitir uma comunicação. Esse aspecto dos estudos da comunicação, aliás, está presente na abordagem de vários outros teóricos, desde o pioneiro Lasswell (1948) e sua fórmula (quem $\rightarrow$ diz o quê $\rightarrow$ em que $\rightarrow$ canal para quem $\longrightarrow$ com que efeito) até os mais atuais, como McQuail e Windhal (1993), Barker e Gaut (2001), Curral e Chambel (2001) entre inúmeros outros autores. 


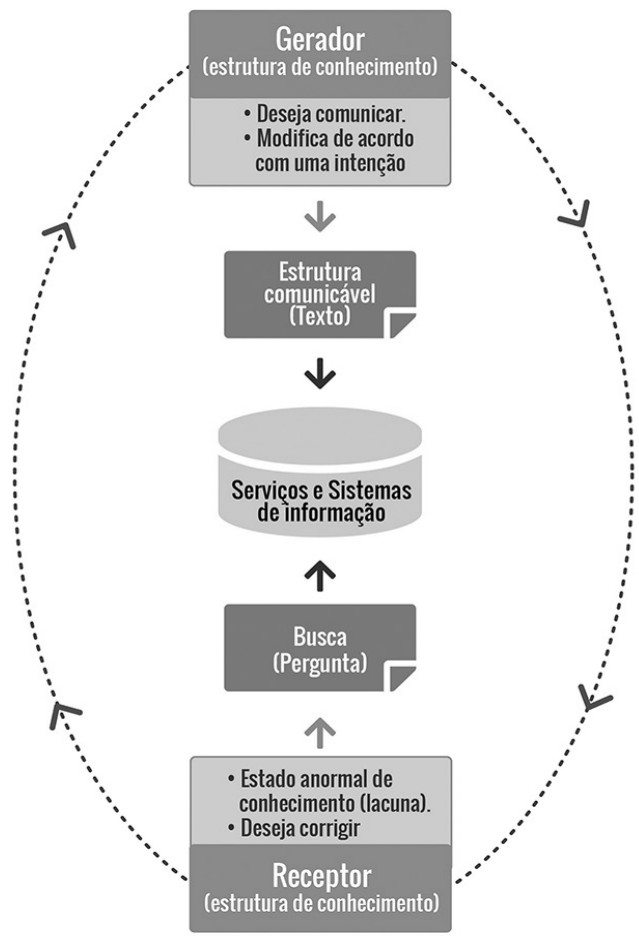

Figura 2. Processo de comunicação da informação estudado no nível linguístico Fonte: adaptado de Belkin (1978:81)

No nível cognitivo, a abordagem de Belkin (1978) centra-se nas transformações ocorridas nos estados (ou estruturas) de conhecimento do indivíduo, quando este recebe a informação capaz de preencher uma necessidade ou lacuna em sua estrutura cognitiva. De fato, o que o autor chama de "estado anormal (ou anômalo) de conhecimento" pode ser entendido como necessidade de informação, dúvida, falha, lacuna na estrutura cognitiva. Essa abordagem, por sua vez, encontra eco na equação fundamental de Brookes (1980) para a Ciência da Informação (Figura 3), pois foca nas mudanças provocadas por uma informação nova na estrutura de conhecimento do indivíduo.

O estudo de necessidades de informação, de comportamento na busca por informação, de uso da informação e de estados/estruturas de conhecimento embute os conceitos que constituem o estudo de comportamento informacional, estabelecendo - embora não somente - o foco da gestão da informação e do conhecimento na Ciência da Informação, discutido mais adiante. 


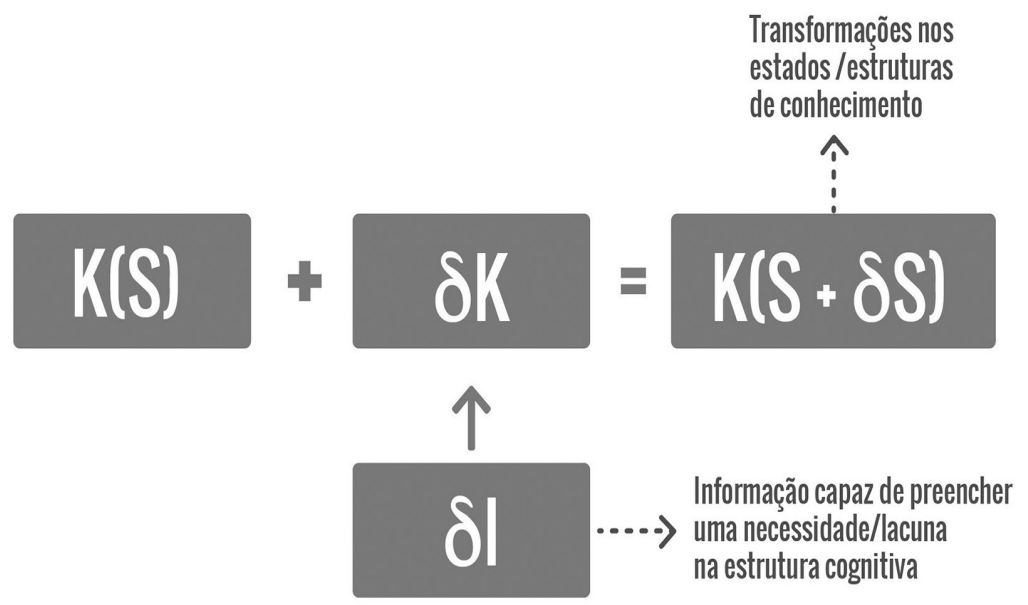

K(S): estrutura atual de conhecimento

SK: novo conhecimento, obtido por meio de $\delta$ I ठl: nova informação

$\delta S$ : efeito da modificação de $\delta$ I

$K(S+\delta S)$ : novo estado de conhecimento

Figura 3. Transformações na estructura de conhecimento do indivíduo, provocadas por uma informação nova, estudada no nível cognitivo, como proposto por Belkin e de acordo com Brookes

Fonte: adaptado de Brookes (1980:131)

Um esforço maior permite, na verdade, ver, nos dois níveis em que é expresso o conceito de informação de Belkin (1978), a comunicação como parte da gestão (e vice-versa). No primeiro - nível lingüístico - o autor aborda o processo de comunicação entre um gerador e um receptor, com todas as suas especificidades (intenção, propósito, estrutura conceitual, entre outras). No segundo - nível cognitivo - o autor fornece os elementos necessários para o foco da gestão do conhecimento (que embute a gestão da informação) na Ciência da Informação. Isso porque Belkin relaciona a informação a algo que muda o estado de conhecimento do indivíduo. Isso, é importante ressaltar, exige de profissionais, produtos, serviços e sistemas, sintonia fina entre estados de conhecimento dos usuários e acervos (disponíveis e acessíveis) de informação.

O tratamento a ser dado a esses acervos e o tornar disponíveis serviços e produtos deles resultantes estão nas preocupações da gestão da informação. Por outro lado, os efeitos ou benefícios dos resultados obtidos, isto 
é, a criação de conhecimento a partir da informação obtida e assimilada, sua aplicação nos melhores cursos de ação (inteligência), e seu compartilhamento em ambientes e comunidades específicas, no foco da gestão do conhecimento. Esta, por sua vez, requer, necessariamente, processos de comunicação da informação. Em suma, a abordagem de Belkin permite tanto fundamentar os estudos da comunicação da informação, quanto identificar bases para estudos da gestão da informação e da gestão do conhecimento no âmbito da Ciência da Informação.

Em relação à questão da gestão, Teixeira Filho (2001), por exemplo, comenta que a comunicação é um de seus componentes cruciais. Alguns estudos têm comprovado isso, especialmente no que concerne ao ambiente das organizações, isto é, em relação à comunicação organizacional e à gestão do conhecimento organizacional. Leite e Costa (2007) dão um passo à frente nessa discussão ao estudarem essa relação também no ambiente acadêmico, envolvendo a comunicação científica e a gestão do conhecimento científico.

Sem dúvida, esse tipo de discussão contribui para as construções teóricas em que a comunicação tem sido estudada, com dois enfoques, principalmente. O primeiro, em relação aos processos de comunicação ocorrendo em diferentes contextos (científico, organizacional, comunitário, tecnológico e para negócios, com ênfase maior nos dois primeiros). O segundo, relacionado à gestão do conhecimento. Brookes (1980) explora melhor a questão norteadora dos estudos de gestão da informação e do conhecimento na Ciência da Informação. Suas ideias estão resumidamente discutidas a seguir.

\section{FOCO NA GESTÃO DA INFORMAÇÃO E DO CONHECIMENTO, A PARTIR DO PENSAMENTO DE BROOKES}

É importante iniciar esta discussão destacando o entendimento de diferentes autores sobre a relação entre a gestão do conhecimento e a gestão da informação. Como resumiu Leite, após ampla análise da literatura e reflexões sobre os temas,

a gestão do conhecimento engloba as práticas e metodologias de gestão da informação, especialmente no que concerne aos processos relacionados à coleta, armazenamento, recuperação de parte do conhecimento tácito, o qual é reduzido a estruturas de informação. Entretanto, a gestão do conhecimento não pode ser reduzida a, nem confundida com a gestão da informação. Isso porque quando o tipo de compartilhamento do conhecimento exige que ele seja veiculado por meio de sistemas formais que permitem o seu armazenamento e recuperação, o conhecimento é, de fato, reduzido a estruturas de informação. Esta, no entanto, poderá desencadear a criação de conhecimento no indivíduo. (Leite, 2006: 98) 
Nessa perspectiva, a maioria dos autores estudiosos da Ciência da Informação considera que a área deve se ocupar do que Le Coadic (1996), entre outros autores, chama de conhecimento registrado. Críticos da gestão do conhecimento, de fato, consideram que o conhecimento, uma vez registrado ou passível de ser registrado, é informação. Bouthillier e Shearer (2002), no entanto, consideram o argumento de que conhecimento registrado (ou explícito) é informação como uma "avaliação inadequada das dimensões qualitativas dos vários tipos de informação e de conhecimento criados, usados e transferidos".

Entre as interessantes abordagens que discutem a relação entre informação e conhecimento está a Teoria do Conhecimento Objetivo de Popper (1975). Brookes (1980) se apropria desta perspectiva e a aplica ao campo da Ciência da Informação, dando vazão a um ambiente teórico fértil para a discussão das relações entre gestão da informação e do conhecimento nesta disciplina.

Com base na abordagem dos Três Mundos de Karl Popper, Brookes propõe uma relação entre informação e conhecimento nos estudos da Ciência da Informação baseada, principalmente, na noção de "espaços mentais únicos". $\mathrm{O}$ autor chama a atenção para o fato de que os eventos do Mundo 2 - individualidades mentais - ocorrem em espaços individuais privados, sendo, portanto, subjetivos. Para objetivá-los, é necessário expressá-los e depositar os registros no Mundo 3, onde são acessíveis a outros e podem, portanto, ser criticamente considerados.

Brookes explora o Mundo 3 de Popper como o da Biblioteconomia e da Ciência da Informação, ressaltando, entretanto, que o trabalho prático dos profissionais da área é coletar e organizar para uso os registros do Mundo 3. Suas atribuições teóricas, segundo o autor, são o estudo das interações entre o Mundo 2 e o Mundo 3, para os descrever e explicar, se puderem, e, então, ajudar na organização do conhecimento, mais do que de documentos, para o uso mais efetivo. Uma observação importante do autor para os estudos da gestão do conhecimento na Ciência da Informação, a partir das abordagens dos três mundos de Popper, é a de que:

Essa abordagem, portanto, permite-nos escapar das subjetividades da velha abordagem de 2000 anos para as teorias do conhecimento e da psicologia subjetiva, assim como da filosofia tradicional. Mais que isso, ao adotar a interação entre os Mundos 2 e 3 como nosso campo de estudos, nós estamos reivindicando a propriedade de uma disciplina que nenhuma outra disciplina já reivindicou. (Brookes, 1980: 128) 
O argumento do autor, como pode ser notado, e que está explicito em seu texto, é de que a Ciência da Informação não deveria ser uma combinação de abordagens de várias disciplinas, como a linguística e ciência da computação, entre outras. Isso porque a área tem, na verdade, segundo o autor, seu próprio território, seus próprios problemas e sua visão própria dos problemas humanos. Uma das leituras possíveis do argumento de Brookes diz respeito ao que se estuda como gestão do conhecimento. Nessa perspectiva, a conclusão das reflexões apresentadas por Batista, Costa e Alvares (2007), após estudo minucioso do pensamento de Brookes em que estas questões são discutidas, é de que

a análise do modelo de Nonaka e Takeuchi [...] mostra que é a Gestão do Conhecimento que, ao se preocupar em descrever e analisar os processos de conversão das duas formas de conhecimento (tácito ou subjetivo e explícito ou objetivo) realiza a segunda proposta feita por Brookes aos cientistas da informação, isto é, estudar as interações entre os Mundos 2 e 3 de Popper. (Batista, Costa e Alvares, 2007)

Sem detalhar mais a abordagem de Brookes, é interessante retomar imediatamente sua proposta de uma "equação fundamental para a Ciência da Informação", ilustrada na Figura 3. Como é possível perceber, a estrutura (ou estado) de conhecimento do indivíduo muda para uma nova estrutura, modificada por uma informação. Note-se que a mesma informação ( $\partial \mathrm{I})$ pode ter diferentes efeitos em diferentes estruturas de conhecimento. Nesse sentido, Brookes considera que, sendo a informação uma pequena porção do conhecimento, seria correto substituir a notação $\partial \mathrm{I}$ pela notação $\partial \mathrm{K}$ na equação.

Observe-se, ainda, que o que Brookes chama de "espaços mentais únicos" pode, perfeitamente, ser considerado como o que Nonaka e Takeuchi (1997) chamam de "conhecimento tácito". Assim, o que Brookes chama de "objetivação" dos espaços individuais fornece a base para os processos de conversão do conhecimento de Nonaka e Takeuchi, mais especificamente, os processos de socialização e externalização. Vale ainda a pena ressaltar que os dois autores basearam sua abordagem nos trabalhos de Sveiby (1994), um dos "pais" da gestão do conhecimento. Mais que isso, têm tido seu trabalho como norteador das abordagens de estudos da gestão do conhecimento na Ciência da Informação, como, por exemplo, em Choo (2003).

Acrescente-se a essas questões a definição de Teixeira Filho (2001) de que a comunicação é um componente crucial da gestão do conhecimento, porque trata de fazer com que "o conhecimento útil chegue à pessoa certa, em tempo hábil, de forma compreensível”. É importante notar que a definição de Teixeira Filho assemelha-se à de Mason (1990), cujo artigo sobre 
profissional da informação foca essas questões, as quais têm sido consideradas como sendo a base da gestão da informação e do conhecimento na Ciência da Informação. A preocupação, portanto, é que o conhecimento seja compartilhado o mais efetivamente possível. Ressalte-se, uma vez mais, que a gestão da informação é parte constitutiva da gestão do conhecimento. Vê-se, portanto, de modo claro, a contribuição de teóricos reconhecidamente da Ciência da Informação, como Brookes e Belkin, entre outros, para a fundamentação dos estudos realizados na Ciência da Informação sobre gestão da informação e do conhecimento.

A Figura 4 ilustra a reflexão sobre a Ciência da Informação e as abordagens de Belkin, Brookes, Popper e Nonaka e Takeuchi, além de autores da comunicação, da gestão da informação e do conhecimento. Entretanto, contribui para reflexão sobre os diálogos entre a comunicação e a gestão na Ciência da Informação, como na seção a seguir.

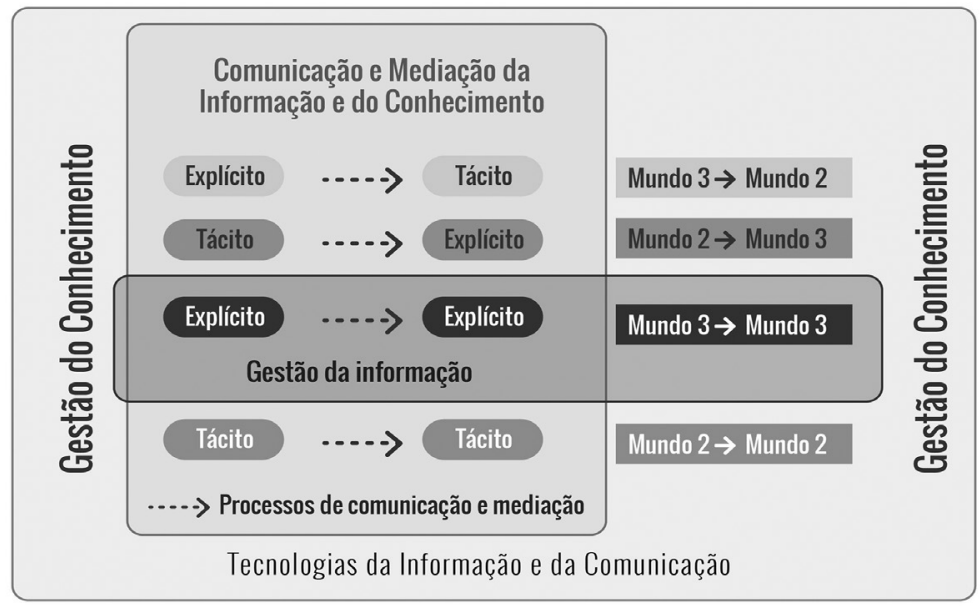

Figura 4. Relações entre comunicação e gestão da informação e do conhecimento para Ciência da Informação, sob a ótica de Brookes Fonte: os autores

\section{DiÁLOGOS ENTRE COMUNICAÇÃO E GESTÃO NA CIÊNCIA DA INFORMAÇÃO}

As argumentações que sustentam as relações entre gestão da informação e do conhecimento e os processos de comunicação são apresentadas nesta seção. Em um primeiro momento, a partir da própria definição de Ciência da Informação de Borko (1968), associada a perspectivas de outros autores, discute-se, 
com base nos fenômenos entendidos como centrais e indissociáveis na área, as relações entre comunicação da informação e gestão da informação. No segundo momento, discute-se a relação entre gestão do conhecimento e processos de comunicação. Em ambas as subseções, dá-se vazão ao diálogo necessário entre comunicação e gestão no âmbito da Ciência da Informação.

\section{Comunicação e gestão da informação}

A definição apresentada por Borko (1968) está repleta de pistas que revelam os interesses mais imediatos da Ciência da Informação. Mais especificamente quando afirma que a área se preocupa com o corpo de conhecimentos relacionados com a origem, coleta, organização, armazenamento, recuperação, interpretação, transmissão, transformação e utilização da informação, Borko descortina duas grandes bases norteadoras tanto da investigação quanto da prática no campo. Isso porque os fenômenos considerados por Borko incluem tanto questões da comunicação da informação, em uma perspectiva mais ampla, quanto questões da gestão da informação, como perspectiva intermediária. Ambas as propostas são brevemente discutidas a seguir.

As questões da comunicação da informação estão clara e amplamente consideradas na definição de Borko (1968). O autor destaca origem e utilização da informação, posicionadas coerentemente como o primeiro e o último fenômeno na definição, os quais remetem a dois importantes elementos ora entendidos como atores ora como processos -, presentes na comunicação humana. O primeiro, a origem (emissores/produtores) e o segundo, a utilização (receptores/usuários).

Nesta linha de raciocínio, considera-se que a comunicação da informação entre seres humanos - assim como toda a dinâmica existente entre a origem e o uso da informação -, corresponde ao interesse mais amplo da Ciência da Informação e está presente na definição de Borko (1968). Alguns autores reclamam este como, de fato, o interesse central da área, como resumidamente apresentado a seguir.

Vickery (1973) considerou que o interesse da área desde o seu surgimento foi a facilitação da transmissão da informação entre seres humanos. Mais tarde, Vickery e Vickery (1987), observam que a Ciência da Informação investiga a comunicação da informação na sociedade, à época centrada em fenômenos específicos (organização da informação, recuperação da informação e disseminação da informação).

De modo coerente com esses autores, Ingwersen (1992) sugere que a área está predominantemente preocupada com o estudo de fenômenos ligados à geração, comunicação e utilização da informação. Perceba-se que Ingwersen 
inclui os processos mencionados no início e no fim da definição de Borko, origem e utilização, sendo que a comunicação por ele mencionada corresponde à dinâmica existente e viabilizadora dos dois processos destacados. Voltando a Belkin (1978), observa-se que sua abordagem não foge a esta noção, ao afirmar que a área visa a produzir conhecimento sobre a facilitação da efetiva comunicação de informação desejada - incluindo nesse momento um forte componente cognitivo -, entre geradores e usuários humanos. Perceba-se, ainda, que Belkin também enfatiza a origem e a utilização, dois elementos centrais da comunicação humana.

Por fim, Saracevic (2010), em verbete da Encyclopedia of Library and Information Sciences, afirma que a área dedica-se às questões científicas e à prática profissional voltadas para os problemas da efetiva comunicação da informação entre os seres humanos no contexto social, institucional ou individual do uso e das necessidades de informação. São estas, portanto, as noções que fundamentaram a ideia de que, partindo da definição seminal de Ciência da Informação apresentada por Borko, a qual se apoia posteriormente em outros estudiosos, a comunicação da informação entre seres humanos constitui o interesse mais amplo da Ciência da Informação.

Ao dar-se destaque à comunicação da informação entre seres humanos como o interesse mais amplo da área, representada pelas interações entre produtores e usuários da informação, quais seriam, então, os fenômenos mais específicos? A resposta a esta pergunta remete a processos justapostos pelo autor entre a origem e a utilização da informação. Ou seja, as questões relacionadas com o estudo da gestão da informação estão inteiramente relacionadas com os fenômenos intermediários, posicionados entre a origem e a utilização da informação na definição apresentada por Borko. São fenômenos intermediários: a coleta, a organização, o armazenamento, a recuperação, a interpretação, a transmissão, a transformação e a utilização da informação. Nessa perspectiva, sugere-se que a interação entre produtores e usuários da informação ou, dito de outra forma, a criação da correspondência efetiva entre necessidades de informação e acervos de informação, constitui processo de comunicação que somente é viabilizado por meio da sistematização dos processos de gestão da informação. Os processos de gestão da informação, por seu turno, equivalem aos fenômenos intermediários encontrados na definição de Borko.

A despeito da definição apresentada por Borko (1968) datar da década de 1960 do século passado, os elementos que a constituem tornam-na atemporal, na medida em que chamam a atenção para fenômenos essenciais até os dias atuais e, certamente, daqui por diante. Tais fenômenos, mesmo não sendo os únicos, parecem estar inteiramente presentes na essência da investigação que 
se realiza na área até os dias de hoje. Desse modo, a construção teórica aqui discutida pode ser representada pela Figura 5.

Tanto para a investigação quanto para a aplicação de conhecimentos na solução de problemas reais relacionados com a melhoria da comunicação da informação entre seres humanos, a Ciência da Informação se vale da perspectiva de processos de gestão da informação. Quer-se dizer com isso que os processos mais básicos de gestão da informação, nomeadamente coleta, organização, armazenamento, preservação, recuperação e disseminação, são essenciais para efetiva comunicação entre produtores (origem) e usuários (uso) da informação.

Para explicar a teoria embutida no modelo representado pela Figura 5, chama-se a atenção para quatro aspectos cuja essência ilustra o entendimento da relação indissociável entre comunicação e gestão da informação e a necessidade do diálogo entre as duas perspectivas.

O primeiro aspecto é a presença dos elementos do sistema de comunicação de interesse da Ciência da Informação, propostos por Belkin e presentes na equação fundamental Brookes (1980), discutidos anteriormente.

O segundo aspecto diz respeito aos atores do sistema de comunicação, produtores e usuários. É importante destacar que a produção e o uso da informação são atividades realizadas pelos mesmos indivíduos em momentos e contextos distintos. Como ilustrado na Figura 5, a geração de conhecimento por parte de produtores é uma decorrência de, entre outros fatores, necessidades de informação plenamente satisfeitas. Ou seja, produtores são necessariamente usuários de informação. Em suma: na medida em que usuários satisfazem suas necessidades de informação geram novos conhecimentos e o ciclo da comunicação da informação é repetido.

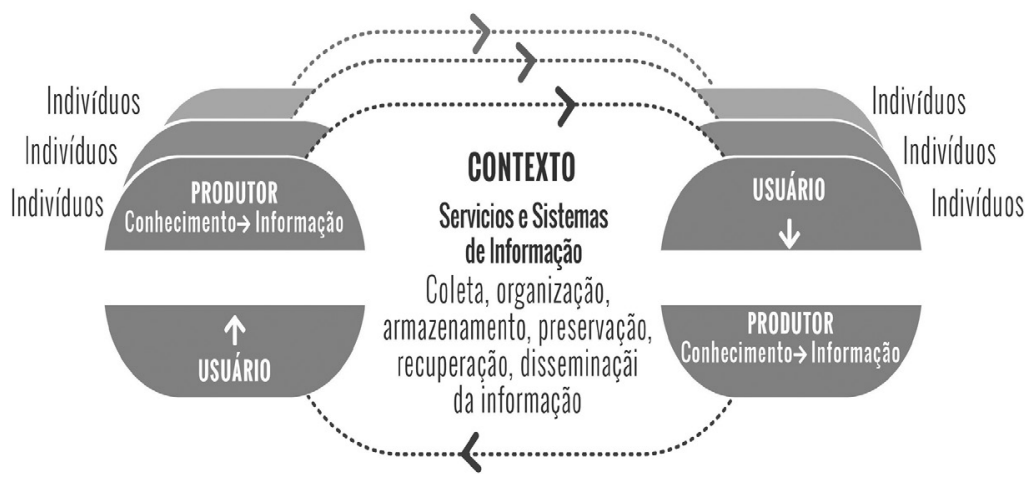

Figura 5. Relações conceituais entre Comunicação e Gestão da informação

Fonte: os autores 
O terceiro aspecto, por sua vez, chama a atenção para o elo responsável pela conexão e interação de produtores e usuários: os serviços e sistemas de informação, constituídos a partir de tecnologias de informação e comunicação viabilizadoras das condições para que haja a plena correspondência entre a informação produzida (origem) e necessidades de informação (utilização). A operacionalização da interação de produtores e usuários está, portanto, na gestão da informação realizada pelos serviços e sistemas de informação, genericamente compreendida pelo conjunto de processos relacionados com a coleta, organização, armazenamento, preservação, recuperação e disseminação da informação.

O quarto e último aspecto trata do contexto em que tanto a comunicação quanto a gestão da informação operam. Por contexto entende-se o conjunto de fatores de ordem cognitiva, social, cultural, política, tecnológica, econômica e legal que, em alguma medida, exerce influência sobre a comunicação e a gestão da informação. Elementos e processos de comunicação e de gestão da informação estão presentes, invariavelmente, em qualquer contexto. O conjunto de forças particulares de cada contexto imprime especificidades no comportamento de quem produz, comunica e utiliza informação. Por esta razão, a despeito dos mesmos elementos, assume-se que contextos influenciam a comunicação e, em decorrência disso, requerem serviços e sistemas que considerem especificidades decorrentes dessa influência.

Em síntese, a definição de Ciência da Informação apresentada por Borko (1968) oferece todos os elementos necessários para a compreensão de que o interesse mais amplo da área por investigar e propor melhorias para a comunicação da informação entre seres humanos embute a investigação e proposição de melhorias da gestão da informação em qualquer contexto.

Como dito anteriormente, a perspectiva proposta não esgota o conjunto de interesses da Ciência da Informação, mas representa a essência de fenômenos centrais sob os quais a área vem produzindo saberes que constituem talvez suas bases mais sólidas. Evidentemente, ao longo de quase sete décadas desde seu surgimento, a área expandiu consideravelmente tanto seus olhares quanto suas práticas. Mais que isso, emanaram fenômenos outros direta ou indiretamente relacionados com a comunicação e gestão da informação. Considerando-se que questões ligadas ao estudo da gestão do conhecimento não estavam nas preocupações dos estudiosos da Ciência da Informação - quiçá de nenhuma disciplina - na década de 1960, é compreensível que não estejam presentes nos fenômenos descritos por Borko. Contudo, apresentam-se a seguir aspectos que sinalizam a convergência possível da gestão do conhecimento e a comunicação no âmbito da Ciência da Informação, identificada desde as abordagens de Brookes (1980) para a Ciência da Informação, como já discutido anteriormente. 


\section{Comunicação e gestão do conbecimento}

O pressuposto básico da argumentação que sustenta relação entre a comunicação e a gestão do conhecimento é que a primeira, em seu aspecto da interação humana e, não reduzida, mas, apoiada nas tecnologias, é um dos processos essenciais para o sucesso da gestão do conhecimento. Uma breve análise da literatura ofereceu uma série de argumentos que corroboram tal pressuposto.

Conforme pontuou Leite (2007), Jensen (1998) considera que a comunicação e a gestão do conhecimento estão ligadas. A diferença entre uma e outra, segundo a autora, é que a gestão do conhecimento é um pouco mais disciplinada em capturar, organizar e rastrear o que nós necessitamos para tomar decisões, enquanto que a comunicação está mais voltada para as trocas. Na mesma linha de raciocínio, Ash (2000) afirma que uma comunicação efetiva é essencial para qualquer programa de gestão do conhecimento. Martensson (2000) e Sharp (2003) enumeraram elementos críticos para o sucesso da gestão do conhecimento, incluindo, entre estes, a comunicação.

Tais definições induzem à consideração de que há relação de complementaridade e interdependência entre as duas práticas. Isso porque, por um lado, a gestão do conhecimento disciplina, sistematiza e torna mais efetivo os processos de comunicação. Por outro, a comunicação permite que a gestão do conhecimento seja viabilizada, na medida em que possibilita, dentre outros processos, a interação entre indivíduos e, por consequência, a criação, compartilhamento e uso do conhecimento (Leite, 2007).

Muito embora a questão da comunicação seja ressaltada como importante no âmbito da gestão do conhecimento, parecem ser raras as iniciativas de gestão do conhecimento que, de fato, levam em consideração os processos de comunicação - e não somente as tecnologias -, como uma camada essencial de um projeto de gestão do conhecimento. De fato, pouco se tem dito a respeito da comunicação - do ponto de vista de seus processos -, como um elemento da gestão do conhecimento. Ao considerar a comunicação sob o aspecto das tecnologias, o discurso da gestão do conhecimento apresenta-se reducionista. Por outro lado, a comunicação deve ser vista como um elemento de forte influência no desempenho das atividades organizacionais, sobretudo na gestão do conhecimento, uma vez que é responsável pelo compartilhamento de conhecimento, pela aprendizagem e pela difusão da cultura na organização (Leite, 2007).

Ives, Torrey e Gordon (1998) afirmam que Platão percebeu que a tradição oral de aprendizagem era baseada no diálogo, enquanto que na tradição escrita o aprendiz tem pouca habilidade para conversar com o criador do 
conhecimento. Isso porque, segundo os autores, a criação do conhecimento é resultado da interação entre dois pontos de vista. Os autores acrescentam que é possível que a reintrodução do diálogo - agora em níveis globais, graças ao desenvolvimento de tecnologias de comunicação -, pode iniciar uma das maiores contribuições cognitivas para a atual fase da gestão do conhecimento. Em argumento semelhante, Theunissen (2004) afirma acreditar que o insucesso de projetos de gestão do conhecimento que estão centrados nas tecnologias está diretamente relacionado ao argumento de Ives, Torrey e Gordon (1998), de que o conhecimento é criado por meio de diálogo. Isto é, segundo Theunissen, comunicação entre dois pontos de vista.

A construção teórica de Kuhlen (2004) fundamenta a reflexão e os relacionamentos construídos até aqui entre processos de comunicação e gestão do conhecimento. Nesse sentido, o autor discute duas abordagens para a gestão do conhecimento: o Knowledge Warehouse Paradigm e Communicative Paradigm.

O Paradigma do Estoque de Conhecimento considera a gestão do conhecimento sem levar em conta os processos de comunicação. Kuhlen considera os modelos de Nonaka e Takeuchi (1997), Wiig (2002) e Probst, Raub e Romhardt (2002) como representantes do Knowledge Warehouse Paradigm. $\mathrm{O}$ autor afirma que, com o advento das tecnologias de comunicação em grande escala, é possível observar uma mudança de paradigma, de uma visão mais estática da produção, da disseminação e do uso do conhecimento e da informação para uma visão dinâmica e colaborativa desses processos, principalmente no que diz respeito à geração e troca do conhecimento. Esta nova visão o autor denomina de Communicative Paradigm, ou paradigma comunicativo da gestão do conhecimento (Leite, 2007).

$\mathrm{Na}$ abordagem do Paradigma Comunicativo, além de ser levado em consideração o uso das fontes de informação existentes, são enfatizados os efeitos da combinação de indivíduos com diferentes backgrounds e diferentes níveis de expertise, além da manutenção do contexto ou da recontextualização do conhecimento que é compartilhado. A interação social entre indivíduos, a experiência compartilhada e as trocas de conhecimento são tão importantes quanto os próprios estoques de conhecimento (Leite, 2007).

Segundo a linha argumentativa deste artigo, a gestão do conhecimento pode ser compreendida como a criação de condições férteis para que o conhecimento seja construído, compartilhado e utilizado. Os macroprocessos cíclicos de construção, compartilhamento e uso do conhecimento, representados na Figura 6, têm nos indivíduos seus protagonistas e na comunicação seu elemento viabilizador, em razão de três argumentos que justificam a gestão do conhecimento. $\mathrm{O}$ primeiro diz respeito ao fato de que a 
geração de novos conhecimentos tem como partida o uso de conhecimento existente - em sua dimensão subjetiva ou objetiva - previamente comunicado. O segundo diz respeito à dinâmica da interação - informal e formal - necessária ao compartilhamento do conhecimento. O compartilhamento diz respeito à própria ação de comunicar. $\mathrm{O}$ terceiro aspecto, decorrente dos dois anteriores, refere-se ao entendimento de que, entre os pré-requisitos para o uso do conhecimento estão a disponibilidade e a acessibilidade a quem dele necessita.

Dessa maneira, a dimensão comum e integradora dos macroprocessos que compõem a gestão do conhecimento é a comunicação, que engloba e promove o ciclo da construção, compartilhamento e uso do conhecimento. Tal ciclo está pautado nos modos de conversão do conhecimento de Nonaka e Takeuchi (1997), que constituem a teoria de criação do conhecimento nas organizações por eles proposta e aqui estendida para ilustrar, além da criação, o compartilhamento e uso do conhecimento. Esta linha de raciocínio vem ao encontro e reforça o Paradigma Comunicativo da gestão do conhecimento de Kuhlen (2004).

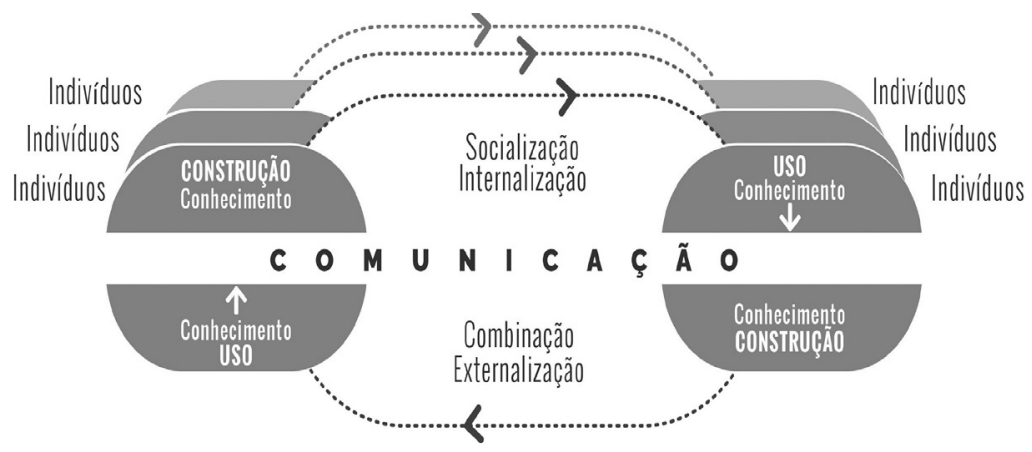

Figura 6. Relações entre comunicação e gestão do conhecimento Fonte: os autores

\section{Considerações finais}

A argumentação epistemológica apresentada resumidamente neste artigo visou a contribuir para o entendimento das relações conceituais entre comunicação da informação, gestão da informação e gestão do conhecimento no contexto da Ciência da Informação, conforme genericamente ilustrado na Figura 7. Como é possível notar, processos de comunicação, em diferentes contextos, são cruciais tanto para a gestão da informação quanto para 
a gestão do conhecimento. Constituem, de fato, um dos focos centrais dos estudos na ciência da informação.

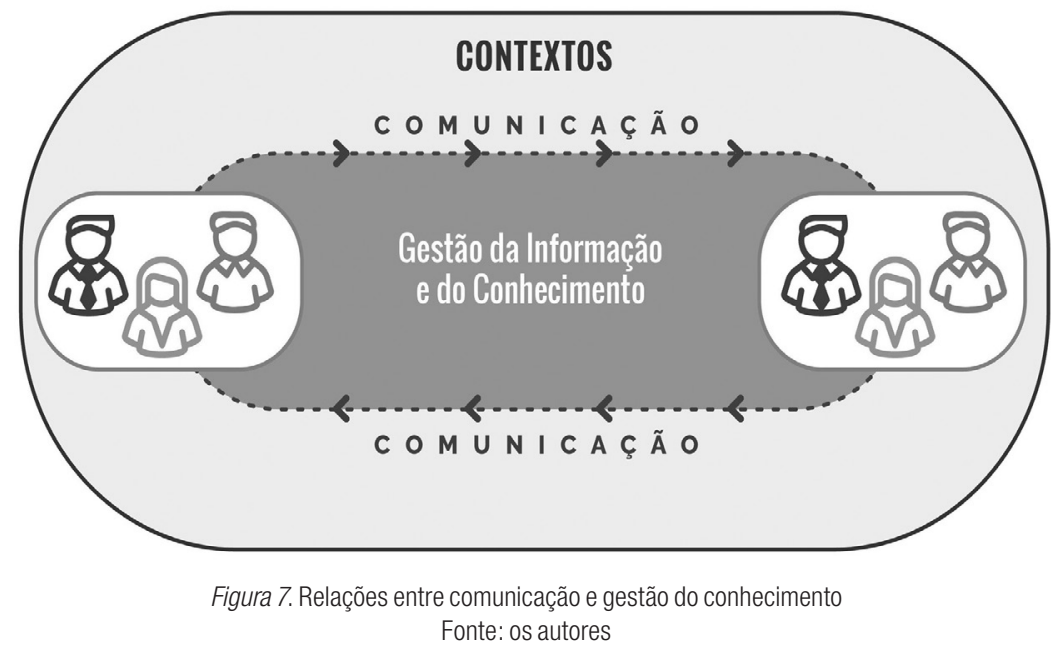

Sugere-se, portanto, com base em argumentos sustentados na literatura que fundamenta e nas construções teóricas, propostas, que é pertinente realizar estudos tanto de comunicação quanto de gestão da informação e do conhecimento, no âmbito da Ciência da Informação, levando pelo menos três questões.

A primeira questão está relacionada com os diferentes contextos em que a comunicação e a gestão ocorrem. Os contextos podem ser entendidos como conjunto de fatores de ordem cognitiva, social, cultural, política, tecnológica, econômica e legal que, em alguma medida, exerce influência sobre a gênese e os fluxos de informação e conhecimento. Por consequência, influenciam também seus processos de gestão e comunicação. São exemplos os contextos da informação científica, informação tecnológica, informação para negócios, informação organizacional, informação para cidadania e comunitária, entre outros.

A segunda questão diz respeito às relações conceptuais entre comunicação e gestão da informação e do conhecimento. Entre as possibilidades de leitura de tais relações, a proposta teórica partiu do pressuposto de que, sob a ótica da Ciência da Informação, conforme discutido ao longo do artigo, processos apropriados de gestão da informação e do conhecimento levam à efetividade da comunicação. Ou seja, a gestão da informação e do conhecimento são condições propulsoras da comunicação entre seres humanos. 
Conversamente, a própria gestão do conhecimento, conforme proposto, depende de processos de comunicação. Isso porque, na medida em que se considerar que os processos de conversão do conhecimento, cerne da teoria de criação do conhecimento de Nonaka e Takeuchi (1997), dizem respeito, de fato, a processos de comunicação. Nesse sentido, considerou-se que a comunicação é crucial para a gestão.

Por fim, é importante considerar que as propostas conceptuais constituem quadros teóricos de referência possíveis, mas não únicos para estudos de comunicação e gestão da informação e do conhecimento sob a ótica da Ciência da Informação. Além disso, ressalta-se a possibilidade de ocorrências pontuais de somente um ou outro destes tópicos (comunicação ou gestão) em estudos na Ciência da Informação, se considerados os conceitos de informação para a área apresentados por autores cujas abordagens - seminais - a fundamentam.

\section{REFERÊNCIAS}

Alves, S. 1997. Revigorando a cultura da empresa: uma abordagem cultural da mudança nas organizações na era da globalização. São Paulo: Makron Books.

Ash, J. 2000. Communication missing from KM's core strategies. http://www.knowledgepoint.com.au/knowledge_management/Articles/KM_JA001.htm

Barker, L. L. e D. Gaut. 2001. Communication, 8. ed. Boston: Allyn \& Bacon.

Batista, F. F., S. M. S. Costa e L. M. A. R. Alvares.2007. "Gestão do conhecimento: a realização da proposta de Brookes para a ciência da informação?”. Encontro Nacional de Pesquisa em Ciência da Informação 8. Salvador. Anais... Salvador: ENANCIB.

Belkin, N. 1978. "Information concepts for information science". Journal of Documentation 34:55-85.

Borko, H. 1968. "Information Science: what is it?". American Documentation 19 (1): 3-5.

Bouthillier, F. e K. Shearer. 2002. "Understanding knowledge management and information management: The need for an empirical perspective". Information Research 8 (1).

Brookes, B. C. 1980. "The foundations of information science. Part I. Philosophical aspect". Journal of Information Science 2: 125-133.

Choo, C. W. 2003. A organização do conhecimento: como as organizações usam a informação para criar significado, construir conhecimento e tomar decisões. São Paulo: Editora Senac.

Curral, L. e M. J. Chambel. 2001. "A comunicação nas organizações", em Manual de psicossociologia das organizações, J. M. Ferrerira, 357-376. Alfragide: McGraw-Hill de Portugal.

Davenport, T. e L. Prusak. 1999. Conhecimento empresarial. Rio de Janeiro: Campus.

Dervin, B. 1977. "Useful theory for librarianship: communication, not information". Drexel Library Quarterly 13 (3): 16-32. 
Farradane, J. 1979. “The nature of information”. Journal of Information Science (London) 1 (3): 13-17.

Farradane, J. 1976. "Towards a true information science". Information Scientist 10 (3): 91-101.

Georgia Institute of Technology. 1962. Proceedings of the Conference on Training Science and Information Specialists. Atlanta: National Science Foundation.

Ingwersen, P. 1992. Information retrieval interaction. London: Taylor Graham.

Ives, W., B. Torrey e C. Gordon. 1998. "Knowledge management: an emerging discipline with a long history". Journal of Knowledge Management 1 (4): 269-274.

Jensen, B. 1998. "Communication or knowledge management? It's time to wake up and smell the koffee". Communication World.

Kochen, M. 1983. "Information and Society". Annual Review of Information Science and Technology 18: 277-304.

Kuhlen, R. 2004. "Change of Paradigm in Knowledge Management: Framework for the Collaborative Production and Exchange of Knowledge", em Knowledge management: libraries and librarians taking up the challenge, H. Hobohm (ed.), 21-38. München: K. G. Saur, IFLA Publications.

Lasswell, H. 1948. "The Structure and Function of Communication in Society", em The Communication of Ideas, L. Bryson (ed.), 32-51. New York: Institute for Religious and Social Studies.

Le Coadic, Y. 1996. A ciência da informação. Brasília: Briquet de Lemos/Livros.

Leite, F. C. L. 2006. "Gestão do conhecimento científico no contexto acadêmico: proposta de um modelo conceitual”. Dissertação (mestrado), Universidade de Brasília.

Leite, F. C. L. 2007. "Comunicação científica e gestão do conhecimento: enlaces conceituais para a fundamentação da gestão do conhecimento científico no contexto de universidades”. Transinformação 19 (2): 139-151. http://dx.doi.org/10.1590/ S0103-37862007000200005

Leite, F. C. L. e S. M. S. Costa. 2007. "Gestão do conhecimento científico: proposta de um modelo conceitual com base em processos de comunicação científica”. Ciência da Informação (Brasília) 36 (1): 92-107.

Martensson, M. 2000. "A critical review of knowledge management as a management tool”. Journal of Knowledge Management 4 (3): 204-216.

Mason, R.O. 1990. "What is an information professional?" Journal of Education for Library and Information Science 31 (2): 122-138.

McQuail, D. e S. Windahl. 1993. Communication models for the study of mass communication. Londres: Longman.

Miller, K. 2006. Organizational communication: approaches and processes, 4. ed. Belmont. CA: Thomson Wadsworth.

Nonaka, I. e H. Takeuchi. 1997. Criação do conbecimento na empresa: como as empresas geram a dinâmica da inovação. Rio de Janeiro: Campus.

Pignatari, D. 1968. Informação, linguagem, comunicação, 2. ed. São Paulo: Perspectiva.

Pinheiro, L. V. R. 2005. "Processo evolutivo e tendências contemporâneas da Ciência da Informação”. Informação E Sociedade: Estudos 15 (1): 1-21.

Popper, K. R. 1975. Conhecimento objetivo: uma abordagem evolucionária. Belo Horizonte: Editora Itatiaia, São Paulo: Ed. da Universidade de São Paulo. (Espírito de Nosso Tempo. V. 13) 
Probst, G., S. Raub e K. Romhardt. 2002. Gestão do conbecimento: os elementos construtivos do sucesso. Porto Alegre: Bookman.

Saracevic, T. 2010. "Information Science", em Encyclopedia of Library and Information Sciences, 3. ed., 2570-2585.

Sharp, D. 2003. "Knowledge management today: challenges and opportunities". Information Processing and Management 20 (2): 32-37.

Smoliar, S. W. 2003. "Interaction management: the next (and necessary) step beyond knowledge management”. Business Process Management Journal 9 (3): 337-353.

Soares, B. J. 2003. "Comportamento de gestores de empresas de base tecnológica na busca e uso de informações”, em Encontro Nacional de Pesquisa em Ciência da Informação 5. Belo Horizonte. Anais... Salvador: ENANCIB.

Sveiby, K. E. 1994. Towards a knowledge perspective on organisation. Dissertation, Doctoral Business Administration, Department of Business Administration, University of Stockholm.

Taylor, R. S. 1966. "Professional aspects of Information Science and Technology". Annual Review of Information Science and Technology 1: 15-40.

Teixeira Filho, J. 2001. "Gestão do conhecimento e comunicação organizacional”. Insight Informal 44.

Theunissen, P. 2004. "Communication: the cornerstone of knowledge management". Making a Difference: Australian and New Zealand Communication Association Conference. University of Sydney, Sydney, Australia, 7-9 July 2004.

Tubbs, S. e S. Moss. 2003. Human Communication: principles and contexts, 9. ed. Boston: McGraw-Hill.

Vickery, B. C. 1973. Information systems. London: Butterworth.

Vickery, B. C. e A. Vickery. 1987. Information science in theory and practice. London: Bowker-Saur.

Wiig, K. M. 2002. Knowledge management has many facets. Knowledge Research Institute. http://www.krii.com/downloads/Four_KM_Facets.pdf

Yovits, M. C. 1969. "Information science: towards development of a true scientific discipline”. American Documentation 20 (4): 369-376.

Para citar este texto:

De Souza Costa, Sely Maria y Fernando César Lima Leite. 2018. "Imbricações teóricas entre comunicação e gestão da informação e do conhecimento na Ciência da Informação". Investigación Bibliotecológica: archivonomía, bibliotecología e información 32 (74): 225 249.

http://dx.doi.org/10.22 201/iibi.24488321xe.2018.74.57923 